\title{
Transgenic expression of epidermal growth factor and keratinocyte growth factor in $\beta$-cells results in substantial morphological changes
}

\author{
M L Krakowski, M R Kritzik, E M Jones, T Krahl, J Lee, \\ M Arnush, D Gu, B Mroczkowski and N Sarvetnick
}

Department of Immunology, The Scripps Research Institute, 10550 North Torrey Pines Road, La Jolla, California 92037, USA

(Requests for offprints should be addressed to N Sarvetnick)

\begin{abstract}
The upregulation of a limited number of growth factors in our interferon- $\gamma$ transgenic model for regeneration within the pancreas lead us to propose that these factors are important during pancreatic regeneration. In this study, we have assessed the influence of two growth factors within the pancreas, epidermal growth factor (EGF) and keratinocyte growth factor (KGF), by ectopically expressing these proteins under the control of the human insulin promoter in transgenic mice. This $\beta$-cell-targeted expression of either EGF or KGF resulted in significant morphological changes, including cellular proliferation and disorganized islet growth. Intercrossing the individual Ins-EGF and Ins-KGF transgenic mice resulted in more
\end{abstract}

profound changes in pancreatic morphology including proliferation of pancreatic cells and extensive intra-islet fibrosis. Insulin-producing $\beta$-cells were found in some of the ducts of older Ins-EGF and Ins-EGF $\times$ KGF transgenic mice, and amylase-producing cells were observed within the islet structures of the double transgenic mice. These data suggest that both EGF and KGF are capable of affecting pancreatic differentiation and growth, and that co-expression of these molecules in islets has a more substantial impact on the pancreas than does expression of either growth factor alone.

Journal of Endocrinology (1999) 162, 167-175

\section{Introduction}

The healthy adult pancreas is a developmentally stable organ with limited mitotic activity. Models allowing the study of pancreatic growth and differentiation are of particular interest because the elimination or dysfunction of pancreatic cells is associated with a number of disease states. In the human autoimmune disease insulindependent diabetes mellitus, there is selective and permanent destruction of the insulin-producing $\beta$-cells in the islets of Langerhans. Pancreatic disorders also affect the duct system, as is observed in chronic pancreatitis and cystic fibrosis (Lack 1989, Sessa et al. 1990, Hootman \& de Ondarza 1993). It appears from these examples of disease that the lost cells are not restored in vivo. Nevertheless, the potential for such cells to regenerate has been shown experimentally (Sarvetnick et al. 1988, Brockenbrough et al. 1988, Rosenberg \& Vinik 1989, Bonner-Weir et al. 1993, Wang et al. 1993, Wang \& Bouwens 1995). We have shown that the ectopic expression of interferon- $\gamma$ $(\mathrm{IFN}-\gamma)$ in the mouse results in regeneration within the pancreas (Gu \& Sarvetnick 1993). Further investigation revealed that the expression of the growth factor epidermal growth factor (EGF) was upregulated in the islets of these transgenic mice (Arnush et al. 1996).
The growth factors required for pancreatic differentiation are not yet fully defined. A survey of potentially critical growth factors, including fibroblast growth factor-2, recombinant human hepatocyte growth factor, insulin-like growth factor-II, platelet-derived growth factor, and nerve growth factor did not identify any factors that could influence the growth of pancreatic bud cultures in vitro. However, EGF and transforming growth factor $\beta-1$ (TGF $\beta-1)$ were able to induce ductal and endocrine cell development respectively (Sanvito et al. 1994). While the ability of EGF to stimulate epithelial cell and fibroblast proliferation is well documented, it has also demonstrated mitogenic properties for pancreatic growth (Dembinski et al. 1982, Logsdon 1986, 1987, Marti et al. 1989, Verme \& Hootman 1990, Mangino et al. 1992). In addition, evidence exists linking the overexpression of EGF and its receptor to both chronic pancreatitis and malignant pancreatic growth (Barton et al. 1991, Korc et al. 1992, 1994, Yamanaka et al. 1993, Friess et al. 1996). Indeed, overexpression of this growth factor could potentially confer a direct growth advantage to pancreatic cancer cells (Korc 1998).

The highly related member of the fibroblast growth factor family, keratinocyte growth factor (KGF), has also been shown to stimulate the proliferation of pancreatic 
ductal epithelial cells in rats after daily systemic injection for 1-2 weeks (Yi et al. 1994). KGF is also involved in wound healing (Werner et al. 1992) and in the differentiation of many epithelial tissues (Aaronson et al. 1990, Alarid et al. 1994). Additionally, KGF is known to profoundly upregulate epidermal cell proliferation (Aaronson et al. 1991). More specifically, we have previously observed that ectopic expression of KGF under the control of the insulin promoter initiated significant intraislet proliferation of ductal cells in the pancreata of transgenic mice (Krakowski et al. 1999).

For our IFN- $\gamma$ transgenic model, a screen for factors potentially involved in the regenerating phenotype yielded both EGF and KGF. Therefore, we chose to study how these two factors might be involved by generating transgenic mice. In this study, we have investigated the influence of these growth factors on pancreatic differentiation by generating transgenic mice which overexpress both EGF and KGF in the $\beta$-cells of the islets of Langerhans. Here we report that co-expression of these growth factors acted in concert to produce striking morphological changes in the pancreas, without causing any apparent abnormalities in pancreatic function.

\section{Materials and Methods}

\section{Transgenic mouse generation}

The $280 \mathrm{bp}$ EGF cDNA was used to generate the Ins-EGF transgenic mouse. The cDNA was cloned into a vector containing the human insulin promoter and the hepatitis B 3'-untranslated sequence. The Ins-EGF fragment was isolated by low melt agarose, purified using Geneclean (BIO101 Inc., La Jolla, CA, USA) and NACS Prepac DNA purification columns (BRL, Gaithersburg, MD, USA), and microinjected into fertilized zygotes from $(\mathrm{BALB} / \mathrm{c} \times \mathrm{C} 57 \mathrm{BL} / 6) \mathrm{F}_{2}$ mice. Progeny were screened for the presence of the transgene by PCR typing of tail DNA that was extracted using proteinase $\mathrm{K}$ digestion overnight. PCR was performed using two 24 -mer primers specific for the human insulin promoter and EGF sequence. Transgene-positive mice were further bred with $\mathrm{BALB} / \mathrm{c}$ mice. The generation of Ins-KGF mice was analogous and has been described elsewhere (Krakowski et al. 1999). Once both lines had been backcrossed to $\mathrm{BALB} / \mathrm{c}$ mice for four generations, individual homozygote Ins-EGF and Ins-KGF mice were mated and progeny interbred to create homozygous, double transgenic $($ Ins-EGF $\times$ Ins-KGF) mice.

\section{Animal husbandry}

All mice were maintained in a specific pathogen-free facility at the Scripps Research Institute according to the rules and regulations of the Institutional Animal Care and
Use Committee. Mice were housed under a controlled $12 \mathrm{~h}$ light: $12 \mathrm{~h}$ darkness cycle and provided with food and water ad libitum.

\section{Histological analysis and immunocytochemistry}

Pancreata were fixed overnight in $10 \%$ neutral buffered formalin $(3.6 \%$ formaldehyde) and embedded in paraffin. Paraffin sections $(5 \mu \mathrm{m})$ were either conventionally stained with hematoxylin and eosin (H\&E) for histological evaluation or stained for the presence of insulin, glucagon, somatostatin, amylase, EGF, EGF receptor or bromodeoxyuridine (BrdU) using immunocytochemical techniques (see Gu \& Sarvetnick 1993, Arnush et al. 1996). Sections were deparaffinized and blocked with 10\% normal goat serum before applying the primary antibodies for insulin, glucagon, amylase or somatostatin (all from DAKO, Carpentaria, CA, USA), or BrdU (Accurate/ Sera-Lab, Westbury, NY, USA). Binding of the primary antibody was detected using the appropriate secondary antibody (Vector Laboratories, Burlingame, CA, USA or Boehringer-Mannheim, Indianapolis, IN, USA), and the horseradish peroxidase (HRP)-labeled avidin-biotin complex (ABC kit; Vector Laboratories). HRP was visualized using 3,3'-diaminobenzidine as a substrate. Gill's hematoxylin was used as a counterstain. Masson's trichrome staining was completed at the Scripps Research Institute Department of Histology. Briefly, paraffinembedded sections were fixed in Bouin's fixative, stained successively with Weigert's iron hematoxylin and with Biebrich scarlet-acid fuchsin acid then counterstained with aniline blue. This results in collagen and mucin staining blue indicating the presence of fibrosis while cytoplasm stains red. Islet size was measured as in Krakowski et al. (1999). Briefly, anti-insulin-stained sections from mice of various ages were examined at $10 \times$ power (Zeiss Axioscope), using the $100 \mu \mathrm{m}$ size of the crosshairs for comparison. Islets were scored as small $(<100 \mu \mathrm{m})$, medium $(200-400 \mu \mathrm{m})$ or large $(>400 \mu \mathrm{m})$. Sixteen Ins-KGF, sixteen Ins-EGF, eleven Ins-EGF $\times$ KGF and twelve non-transgenic mice, including all ages, were examined. Statistical analyses of both young ( $<3$ months) and old ( $>3$ months) mice for mean islet size ( \pm s.E.M.) were compared using the program Statview as described below.

\section{Blood glucose measurement}

At regular intervals (approximately every 2 weeks), blood was obtained from the tail and blood glucose levels were determined using Glucofilm blood glucose test strips (Miles Diagnostic, Elkhart, IN, USA). Non-fasting blood glucose values of non-transgenic $\mathrm{BALB} / \mathrm{c}$ mice in our colony ranged from 80 to $160 \mathrm{mg} / \mathrm{dl}$. 


\section{Glucose tolerance testing}

To determine glucose tolerance over time, transgenic and control littermate mice were fasted overnight and an initial blood glucose reading taken (time zero) as described above. Mice were then injected intraperitoneally with $0 \cdot 2 \mathrm{~g}$ D-glucose $/ 100 \mathrm{~g}$ body weight $(0 \cdot 1 \mathrm{~g} / \mathrm{ml}$ in sterile PBS), and blood glucose measured after $10 \mathrm{~min}$ and again after $60 \mathrm{~min}$.

\section{BrdU labeling}

Cellular proliferation was quantified by injecting $100 \mu \mathrm{g} / \mathrm{g}$ body weight BrdU (Serva, Heidelberg, Germany) intraperitoneally into mice $15 \mathrm{~h}$ prior to their being killed. Paraffin-embedded pancreata were sectioned and stained with an anti-BrdU antibody (Accurate Chemical, Westbury, NY, USA) as described above after treatment with $2 \cdot 8 \mathrm{M} \mathrm{HCl}$ for $15 \mathrm{~min}$. The extent of proliferation was determined by counting all the BrdU-positive cells within 20 fields using a $20 \times$ objective; the area equivalent to one field at this magnification is exactly $4.0 \times 10^{5}$ $\mu \mathrm{m}^{2}$. We specifically made note of whether the positive cell was a duct cell or found within the islet of Langerhans and/or acinar tissue. This measurement of 20 fields was representative of all the BrdU-positive cells per pancreatic slice, yet was also normalized for the area measured for each mouse. Six Ins-KGF, five Ins-EGF, eight Ins-KGF $\times$ EGF and six non-transgenic mice were counted. This allowed the quantification of the average number of BrdU-positive cells ( \pm S.E.M.) per pancreatic slice and statistical analyses.

\section{Statistical analysis}

The analysis of variance (unpaired $t$-test) test was used to compare differences between the groups using the Statview program by Abacus Concepts (Berkeley, CA, USA).

\section{Results}

\section{Generation of Ins-EGF transgenic mice}

To determine the influence of EGF expression in the $\beta$-cells of the pancreas, transgenic mice expressing murine EGF under control of the human insulin promoter were generated (Ins-EGF). Two lines of transgene-positive mice were found when screened by PCR and were further bred with $\mathrm{BALB} / \mathrm{c}$ mice for four generations from the original $(\mathrm{BALB} / \mathrm{c} \times \mathrm{C} 57 \mathrm{BL} / 6) \mathrm{F}_{2}$ mice. No significant differences between the lines were ever observed. These transgenic mice appeared normal and healthy, with average life spans. We characterized expression patterns of EGF by immunohistochemistry. The expression of EGF was found to be significantly upregulated in all transgenic islets (Fig. 1A). As expected, EGF was expressed at low levels in the islets of non-transgenic littermate controls (Fig. 1B). Furthermore, while the level of the EGF receptor (EGF-R) appeared comparable to the low constitutive level of expression previously observed for this receptor (Damjanov et al. 1986, Chabot et al. 1987), we did detect a modest upregulation of the EGF-R in the ductal epithelia of the transgenic pancreas (data not shown).

\section{Morphological changes of Ins-EGF mice}

Ins-EGF transgenic mice had dramatic morphological changes within their pancreata. While the pancreatic ducts appeared normal in the transgenic mice, the islets were found to increase in size as the mice aged. After 3 months of age, these mice had significantly more islets of larger size $(>400 \mu \mathrm{m}$ in diameter) than did their non-transgenic littermates, in which most islets were $<100 \mu \mathrm{m}$ in diameter $(P<0 \cdot 008)$. In addition, the transgenic islets exhibited substantial disaggregation (Fig. 1). We also observed significant fibrosis around the islets (Fig. 1D). Pancreatic lymphocytic infiltration was extremely minor and not sufficient to explain the disorganized architecture of the islets. Surprisingly, the rare lymphocyte infiltration we first observed at 3 months did not increase to any significant level with age (Fig. 1C: Ins-EGF, 3 months and Fig. 1D: Ins-EGF, 17 months). The structural changes in the islets were not observed in non-transgenic littermates (Fig. 1E).

Immunostaining for insulin, glucagon, somatostatin, and amylase in the Ins-EGF mouse revealed typical expression patterns within the islets and exocrine tissue, similar to age- and sex-matched non-transgenic controls (Fig. 2C and D and data not shown for hormones other than insulin). Additionally, the cells producing these proteins were, for the most part, present in typical numbers and placement. However, we did detect the rare presence of insulin-positive cells in some ducts at a later age (Fig. 3A), implying the generation of newly formed $\beta$-cells within the pancreatic ducts; $\beta$-cells are not normally found outside of the islets. In spite of the unusual islet morphology, the overall health and viability of Ins-EGF mice matched that of non-transgenic littermates. Blood glucose values were taken at 2-week intervals for mice of various ages and no mouse exceeded the normoglycemic value of $150 \mathrm{mg} / \mathrm{dl}$, nor was any mouse found to be hypoglycemic.

\section{Synergistic effects of combined EGF and KGF on pancreatic morphology}

We have previously generated a model of intra-islet duct cell proliferation by ectopic expression of KGF under control of the insulin promoter (Krakowski et al. 1999). The expression of KGF in the islets of the pancreas 

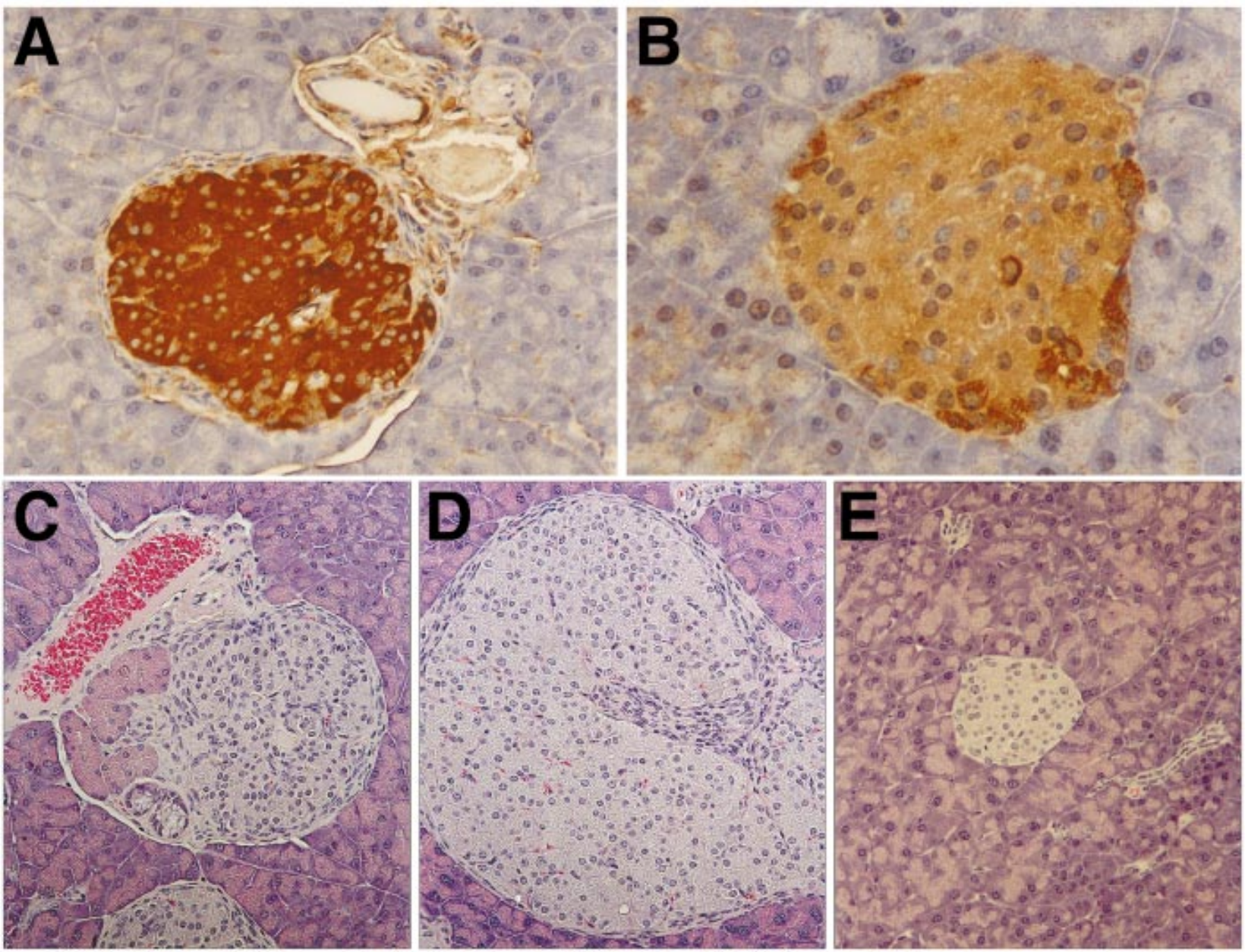

Figure 1 Overexpression of EGF within islets of transgenic Ins-EGF mice leads to disorganization of islet architecture and increases with age. Three-month-old Ins-EGF (A) and age- and sex-matched non-transgenic control littermate (B) both stained with anti-EGF antibody as shown in brown chromagen staining against blue hematoxylin counterstain. Three-month-old (C) and 17-month-old (D) Ins-EGF mice stained with $\mathrm{H} \& \mathrm{E}$, revealing rare and sparse mononuclear cell infiltration to the irregularly shaped islets that increased in size and complexity with age. Age- and sex-matched non-transgenic control littermate stained with H\&E (E), demonstrating typical islet morphology and no immune infiltration. Original magnification of A: $20 \times$ and B: $32 \times, C-E: 20 \times$.

resulted in enlarged islets, with substantial proliferation of duct cells within the islet mass. In addition, we observed the presence of hepatocyte-like (albumin and $\alpha$ fetoprotein-producing) cells in the islets of the KGFexpressing transgenic mice (Krakowski et al. 1999). These pancreatic heptatocytes are easily recognizable as the non-insulin-producing cells that are extremely large in size compared with the other islet cells. Additionally, they are found on the periphery of the islet and are often binucleate (Fig. 2F, see arrowheads). Despite the morphological differences in the pancreata of KGF transgenic mice, no pathology, hyperglycemia, or hypoglycemia were found to be associated with KGF expression in the islets of transgenic mice. To determine the effects that $\beta$-cell expression of these related growth factors would have on pancreatic differentiation and function, Ins-EGF mice were crossed to Ins-KGF mice, and Ins-EGF $\times$ KGF progeny were interbred to homozygosity for both transgenes. Characterization of these double transgenic mice revealed unusual changes in pancreatic morphology which did not simply reflect the effects of each individual transgene.

Ins-EGF $\times$ KGF mice developed enlarged, distended, and non-confluent islets at earlier ages than was seen for either the single Ins-EGF or Ins-KGF transgenic mice. Additionally, all of the transgenic mice, aged 3 months or greater, had significantly more islets of larger size (>400 $\mu \mathrm{m}$ diameter) (Fig. $2 \mathrm{~A}-\mathrm{F}$ ) than did non-transgenic mice (Fig. $2 \mathrm{G}$ and $\mathrm{H}$ ), in which most islets were $<100 \mu \mathrm{m}$ $(P<0 \cdot 02)$. The mean of the number of large islets per pancreatic slice in mice aged 3 months or greater was: 

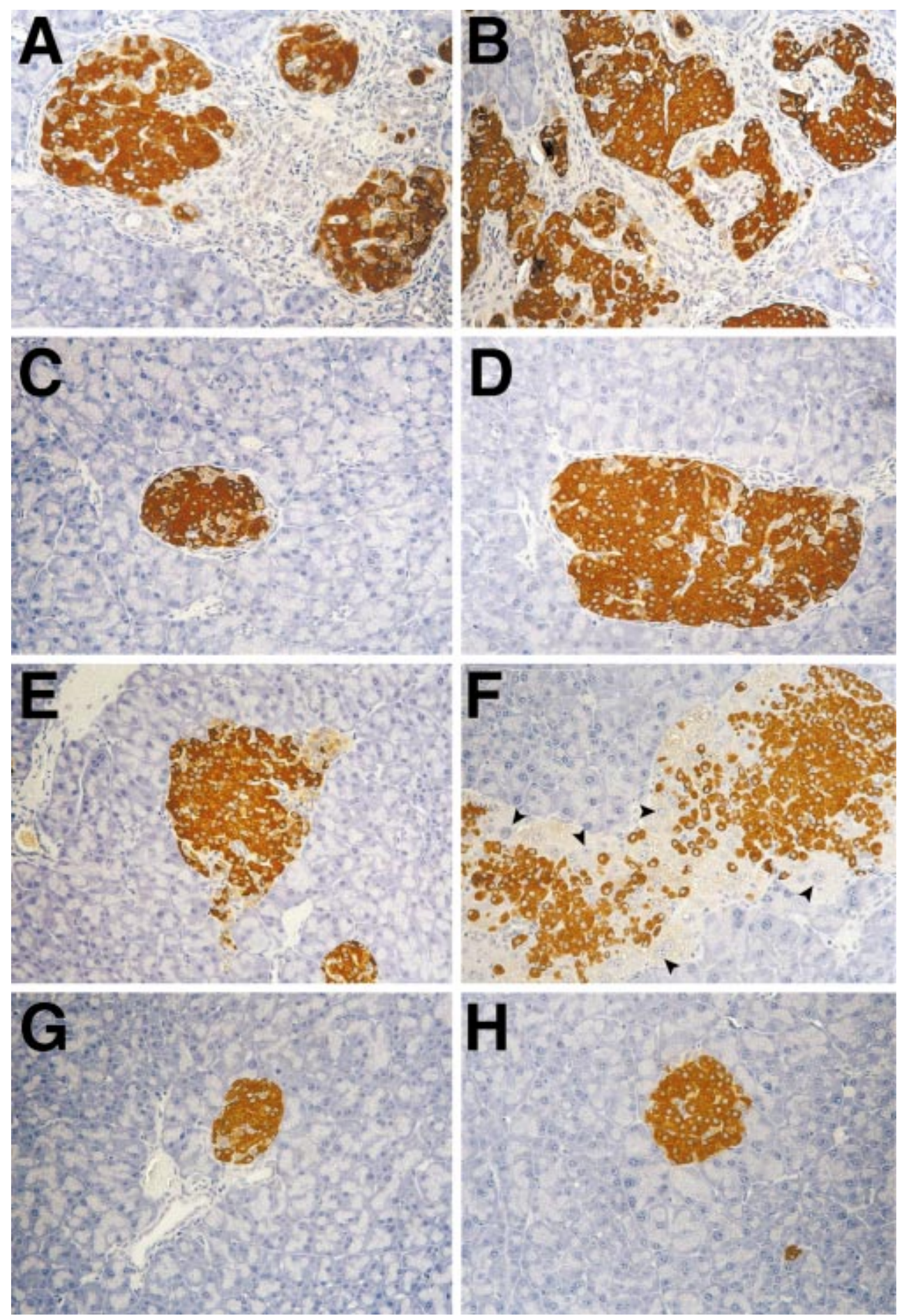

Figure 2 Morphological changes occur at an earlier age in Ins-EGF $\times$ KGF mice, and are more severe than in single transgenic mice. Three-month-old (A) and 6-month-old (B) Ins-EGF $\times$ KGF mice stained with anti-insulin antibody (shown in brown) and counterstained with blue hematoxylin showing increasingly larger, and more disorganized networks of islets. Compare the effects of increasing age from 3 (left panel) to 6 months (right panel) on islet of Langerhans morphology in C, D: Ins-EGF, E, F: Ins-KGF and G, H: non-transgenic (all age-matched) demonstrating delayed and lesser phenotypic changes in single transgenic mice and normal morphology in non-transgenic controls. Arrowheads in panel $\mathrm{F}$ indicate pancreatic hepatocytes within Ins-KGF mouse. Original magnification for all photos was $20 \times$. 

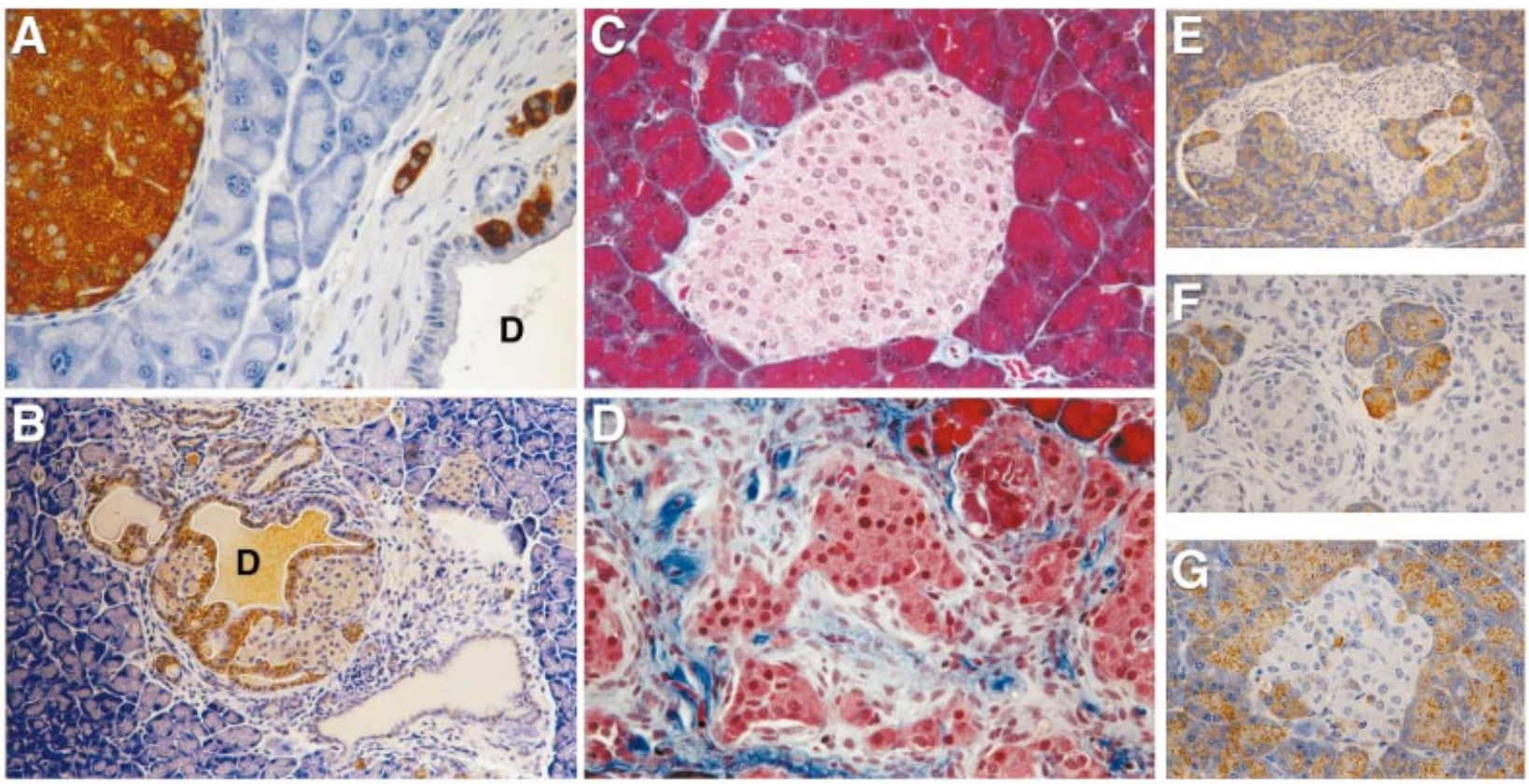

Figure 3 Ins-EGF $\times$ KGF mice have intra-islet ducts, ductal insulin-positive cells, fibrosis and amylase-positive cells within islets of Langerhans. Seventeen-month-old female Ins-EGF mouse stained as in Fig. 2 shows insulin-producing cells within the duct wall (A). Intra-islet duct (designated ' $\mathrm{D}$ ') identified by CAll staining in a 5.5-month-old male mouse (B). Trichrome staining reveals a severe degree of fibrosis within the Ins-EGF $\times$ KGF transgenic mice (4-month-old male) (D) in contrast to the non-transgenic age- and sex-matched littermate (C). Fibrosis within the islets appears as bright blue spindle shaped cells with elongated nuclei, and increases with age (data not shown). Anti-amylase antibody stained with brown chromogen against a blue hematoxylin counterstain reveals atypical endocrine as well as the expected exocrine staining within the pancreata of Ins-EGF $\times$ KGF mice. (E) Early stages of engulfment of acinar tissue by ongoing fibrotic reaction occurring around the islet. (F) Acinar cells staining positive for amylase surrounded by islet tissue and fibrotic cells. (G) Amylase-positive cells without distinct acinar cell morphology within islet tissue. Original magnification of A: $40 \times, B$ : $20 \times, C$ and D: $40 \times$, E: $20 \times$ and $F$ and G: $40 \times$.

Ins-KGF $2 \cdot 7 \pm 0 \cdot 6 \quad(n=8), \quad$ Ins-EGF $3 \cdot 3 \pm 0 \cdot 6 \quad(n=13)$, Ins-EGF $\times \mathrm{KGF} \quad 5 \cdot 5 \pm 0 \cdot 7 \quad(n=4)$ and non-transgenic $0 \cdot 9 \pm 0 \cdot 4(n=8)$. In this regard, the double transgenic mice (Fig. 2A and B) had more islets of larger size than did the Ins-KGF transgenic mice $(P<0 \cdot 02)$ (Fig. $2 \mathrm{E}-\mathrm{F})$, and there appeared to be more islets of a larger size in the double transgenic mice than in the Ins-EGF mice (Fig. 2C and $D)$, although the difference was not as significant $(P<0 \cdot 07)$. Morphological changes to the islets continued to develop as the mice aged. Islet and ductule networks were much larger in the double transgenic mice than in either single transgenic mouse. Furthermore, there appeared to be an increase in the number of intra-islet ductules (a representative intra-islet duct is shown in Fig. 3B). Although islets were enlarged, distended, and lobulated to varying degrees for each transgenic mouse, individual $\beta$-cells remained intact and functional as demonstrated by insulin staining (Fig. 2). Staining for the hormones somatostatin and glucagon revealed typical patterns as seen in non-transgenic littermates (data not shown). Interestingly, as seen in the Ins-EGF mouse, insulin-positive cells were also observed in some of the ducts of the Ins-EGF $\times$ KGF transgenic mice at a later age (6 months) (data not shown).

Normal, non-fasting blood glucose levels were measured over the animal's lifespan $(90-150 \mathrm{mg} / \mathrm{dl})$. Yet the question remained whether these mice regulated their insulin production normally in the face of such unusual morphological changes. All three types of transgenic mice and control mice were analysed with a glucose tolerance test (Wogensen et al. 1993). We observed some inhibition of blood glucose homeostasis immediately following (10-min time-point) the injection of glucose, but after 60 min all mice were indistinguishable and had normalized their blood glucose levels (Table 1). These data may indicate an abnormality in the first phase of insulin release, but no detriment was experienced by the mice as their non-fasting blood glucose levels were normal over their entire lifetimes.

To assess the effects of EGF and KGF on cell proliferation, mice were injected with BrdU; BrdU incorporation into pancreatic cells was determined by immunohistochemistry. The extent of proliferation was determined by counting the number of BrdU-positive cells in 20 fields 
Table 1 Typical pattern of fluctuations in blood glucose. Values are means \pm S.E.M

Blood glucose $(\mathrm{mg} / \mathrm{dl})$

\begin{tabular}{|c|c|c|c|}
\hline \multirow[b]{2}{*}{ Transgene } & & & \\
\hline & $0 \min$ & $10 \min$ & $60 \mathrm{~min}$ \\
\hline Ins-KGF $(n=3)$ & $67 \pm 3$ & $296 \pm 94$ & $116 \pm 29$ \\
\hline Ins-EGF $\times \operatorname{KGF}(n=4)$ & $119 \pm 13$ & $348 \pm 105$ & $122 \pm 16$ \\
\hline Ins-EGF $(n=3)$ & $108 \pm 7$ & $466 \pm 32$ & $141 \pm 109$ \\
\hline $\mathrm{BALB} / \mathrm{C}(n=4)$ & $109 \pm 13$ & $205 \pm 26$ & $128 \pm 12$ \\
\hline
\end{tabular}

Fasting blood glucose concentration $(\mathrm{mg} / \mathrm{dl})$ in all three transgenic and control mice during an intraperitoneal glucose tolerance test of male mice of various ages (range between 3 and 14.5 months) Data are given as the mean and standard error for each type of transgenic. Blood for determination of the blood glucose was taken from the retro-orbital venous plexus during anaesthesia.

per section at $20 \times$ magnification. This measurement was representative of the number of BrdU-positive cells per pancreatic slice. On average, we found that Ins-EGF and Ins-KGF mice had $6 \cdot 8 \pm 2 \cdot 0(n=5$ mice $)$ and $11 \cdot 0 \pm 3 \cdot 8$ ( $n=6$ mice) BrdU-positive cells respectively. In contrast, the double transgenic mice had $15 \cdot 3 \pm 3 \cdot 1(n=8$ mice $)$ and the non-transgenic littermates had $0 \cdot 7 \pm 0 \cdot 3 \quad(n=6$ mice) positive cells. Thus all three lines of transgenic mice had significantly more pancreatic cell proliferation than did the control mice $(P<0 \cdot 01)$. The majority of the proliferating cells of the Ins-KGF mouse had been previously identified as ductal (Krakowski et al. 1999). Morphological examination and statistical comparison ( $t$-test completed for each transgenic mouse), indicated that proliferating cells of the Ins-EGF and of the Ins-EGF $\times$ KGF mice were found to be distributed without bias in the acinar and islet, versus ductal tissues ( $P$ value varied between 0.13 and 0.46 , indicating no significant difference).

As with the Ins-EGF mice, pancreatic lymphocytic infiltration was rare and sparse and did not increase with age in the double transgenic Ins-EGF $\times$ KGF mouse (data not shown). Immunohistochemistry was not completed to characterize the cellular composition of the infiltrates for any of the transgenic mice because of the rarity and subsequent presumed lack of clinical significance the immune cells had for the phenotype. Interestingly, much more extensive intra-islet fibrosis was observed in the double transgenic mice than was observed in the Ins-EGF mice (Fig. 3C and D). As seen in this Figure, the fibrosis is characterized by spindle shaped cells with elongated nuclei. The level of fibrosis increased substantially with age in the double transgenic mice. It is highly probable that the exogenously expressed growth factors are acting, perhaps indirectly, on fibroblasts and other cells of epithelial origin to stimulate this fibrosis. Evidence to support a role for the involvement of growth factors in fibrosis comes from the TGF $\beta$ mouse (Sanvito et al. 1994) as well as those described here.

Unexpectedly, we detected the presence of exocrine cells, which stain positive for amylase, within the islets of double transgenic mice; such positive staining was not observed within the islets of either single transgenic mouse or non-transgenic control. Figure $3 \mathrm{E}-\mathrm{G}$ illustrates the morphology of amylase-positive islet sections, in what we believe to represent progressive stages in the evolution of this phenomenon. That is, it appears that amylase-positive cells are engulfed by the ongoing fibrotic reaction occurring adjacent to islets (Fig. 3E-G), perhaps due to disrupted matrix connections or altered adhesion between cells, after which the membranes of the engulfed cells break down to leave a residual fragment of exocrine tissue, which stains positive for amylase (Fig. 3G). The presence of these exocrine cells within the endocrine (islet) tissue is at least partially responsible for the non-confluent insulin staining we observed in the islets of double transgenic mice, as the cells which produce amylase likely displace the insulin-producing cells.

\section{Discussion}

We have generated a model system in which the expression of KGF and EGF has been targeted to the $\beta$-cells in the islets of Langerhans. KGF and EGF are members of a large family of very similar growth factors. Members of this family have been shown to influence a number of processes, including cell proliferation, migration, and differentiation (Brown 1995). We sought to determine the influence of these molecules on pancreatic development because previous studies have suggested that these molecules might play important roles in this process. For example, previous work by Yi et al. (1994) demonstrated that systemic administration of KGF to rats induced pancreatic duct cell proliferation. The intralobular duct cell proliferation observed was predominantly adjacent to or within the islets of Langerhans, and occurred in the absence of physical injury to the pancreas (Yi et al. 1994). In addition, while investigating the remarkable proliferative and differentiation patterns of the Ins-IFN- $\gamma$ mouse, EGF and EGF-R were found to be upregulated (Arnush et al. 1996). Indeed, EGF has previously been shown to modulate pancreatic growth (Dembinski et al. 1982, Logsdon 1986, 1987, Marti et al. 1989, Verme \& Hootman 1990, Mangino et al. 1992). For example, systemic administration of EGF resulted in the induction of pancreatic duct proliferation in pigs (Vinter-Jensen et al. 1997). While the Ins-EGF $\times$ KGF transgenic mouse enabled us to address the co-operative effects that localized overproduction of these molecules has on pancreatic growth and function, the Ins-EGF and Ins-KGF (described in a separate manuscript; Krakowski et al. 1999) transgenic mice enabled us to assess their influences independently.

Although a low basal level of EGF is normally expressed in the islets of non-transgenic mice, KGF is not normally found at this location. Our transgenic mouse models have demonstrated that expression of EGF and KGF in islet 
$\beta$-cells generates an accelerated and extensive series of changes to both endocrine and exocrine tissues. For example, we have observed significant intra-islet duct cell proliferation in the pancreata of Ins-KGF mice. In addition, we have found that hepatocyte cells exist within the islets of these transgenic mice. Pancreatic cell proliferation was also observed in the Ins-EGF and Ins-EGF $\times$ KGF mice. The Ins-EGF and Ins-EGF $\times$ KGF transgenic mice also exhibited disorganized islets and intra-islet fibrosis as well, both of which were more extensive in the double transgenic mouse. We also found that many features shared by both single transgenic mice, such as pancreatic cell proliferation, increased size and disorganization of islets, and fibrosis, were seen to a greater extent in the double transgenic mice. Interestingly, the amylasepositive cells seen in the double transgenic mice are not found in either of the single transgenic mice, indicating that localized overexpression of both EGF and KGF in $\beta$-cells is required to produce this unique phenotype.

Despite the extensive morphological changes that are observed in the pancreata of growth factor transgenic mice, only very minor deficiencies in pancreatic function were detected. All of the endocrine hormones and exocrine enzymes were present in these transgenic mice, and blood glucose levels remained normal throughout the lives of the animals. Thus the physical changes apparent in these mice did not interfere with normal pancreatic function. Interestingly, some of the pathologies observed also characterize several pancreatic diseases. For example, the GK rat model of non-insulin-dependent diabetes is characterized by disorganized islets, significant fibrosis, and clusters of $\beta$-cells separated by strands of connective tissue (Movassat et al. 1995). In addition, chronic pancreatitis is characterized by inflammation and fibrosis (Steer 1989). Interestingly, in chronic pancreatitis and in some human pancreatic cancers, EGF, EGF-R, and KGF are often overexpressed (Barton et al. 1991, Korc et al. 1992, 1994, Yamanaka et al. 1993, Siddiqi et al. 1995, Friess et al. 1996). These observations suggest that these factors might play a role in disease progression and pathology. For instance, it is possible that altered expression of these critical growth modulators could confer a significant growth advantage to pancreatic cancer cells.

The physiological roles of KGF and EGF in pancreatic development are not clear. Indeed, KGF knockout mice do not appear to have any abnormalities in pancreatic development or function (Guo et al. 1996). However, there is likely to be redundancy within the large family of highly related proteins to which these proteins belong, perhaps masking the contribution of individual factors during development. Such influences would be expected to become more apparent when overexpression of these proteins is localized, perhaps manifest in the phenotypes we observe. Indeed, as discussed earlier, these growth factors do appear to influence pancreatic growth and differentiation, in vivo and in vitro. The observation that several uncharacteristic cell types exist in the transgenic mice overexpressing EGF and KGF in islets also suggests a possible role for these growth factors in pancreatic differentiation. We have detected the presence of insulin-producing cells in the ducts of the Ins-EGF and Ins-EGF $\times$ KGF transgenic mice and of hepatocyte-like cells in the islets of KGF transgenic mice. Thus, EGF and KGF might contribute to pancreatic differentiation by promoting cellular lineage commitment along specific pathways. However, as in any model system, it is possible that the phenotypes exhibited by our transgenic mouse models are due to targeted overexpression in islets and are not reflective of innate physiological influences. Future studies designed to assess the influence of these growth factors on pancreatic growth and differentiation will therefore be important in addressing these critical issues.

In summary, we have developed a transgenic mouse system which will enable us to study the effects of EGF and KGF on pancreatic growth, differentiation, and on the pathologies associated with aberrant overexpression of these growth factors. In addition, the transgenic mice we have produced will enable us to study the generation of the distinct cell types described here, such as the hepatocyte-like cells in the Ins-KGF mice and the ductalendocrine cells in the Ins-EGF and Ins-EGF $\times$ KGF mice. As such, these studies will enhance our understanding of how these critical growth modulators contribute to the growth and differentiation of the pancreas.

\section{Acknowledgements}

The authors would like to heartily thank Gail Patson and Augusta Good who maintained and screened the mouse colony. We would also like to thank Margaret A Chadwell for completing the Trichome stains. The administrative assistance of Joanne Dodge and Jackie Soto is always gratefully appreciated. Drs Marc Horwitz and Malin Flodstrom are thanked for providing provocative scientific discussion.

Grant numbers and sources of support: MLK is supported by an NMSS postdoctoral fellowship, E M J was supported by NIH postdoctoral fellowship DK09355-01, D G was supported by a postdoctoral fellowship from the Juvenile Diabetes Foundation, and N S is supported by a Diabetes Interdisciplinary Research Center from the Juvenile Diabetes Foundation and by NIH grant HD-29764 and JDFI 995010. This is publication 11669-IMM from the Department of Immunology, the Scripps Research Institute.

\section{References}

Aaronson SA, Rubin JS, Finch PW, Wong J, Marchese C, Falco J, Taylor WG \& Kraus MH 1990 Growth factor-regulated pathways in epithelial cell proliferation. American Review of Respiratory Diseases 142 S7-S10. 
Aaronson S, Bottaro D, Miki T, Ron D, Finch P, Fleming T, Ahn J, Taylor W \& Rubin J 1991 Keratinocyte growth factor. A fibroblast growth factor family member with unusual target cell specificity. Annals of the New York Academy of Sciences 638 62-77.

Alarid ET, Rubin JS, Young P, Chedid M, Ron D, Aaronson SA \& Cunha GR 1994 Keratinocyte growth factor functions in epithelial induction during seminal vesicle development. Proceedings of the National Academy of Sciences of the USA 91 1074-1078.

Arnush M, Gu D, Baugh C, Sawyer SP, Davis D, Mroczkowski B, Krahl T \& Sarvetnick N 1996 Growth factors in the regenerating pancreas of gamma-interferon transgenic mice. Laboratory Investigation 74 985-990.

Barton C, Hall P, Hughes C, Gullick W \& Lemoine N 1991 Transforming growth factor alpha and epidermal growth factor in human pancreatic cancer. Journal of Pathology 163 111-116.

Bonner-Weir S, Baxter L, Schuppin G \& Smith F 1993 A second pathway for regeneration of adult exocrine and endocrine pancreas: a possible recapitulation of embryonic development. Diabetes $\mathbf{4 2}$ $1715-1720$

Brockenbrough J, Weir G \& Bonner-Weir S 1988 Discordance of exocrine and endocrine growth after $90 \%$ pancreatectomy in rats. Diabetes 37 232-236.

Brown KD 1995 The epidermal growth factor/transforming growth factor-alpha family and their receptors. European Journal of Gastroenterology and Hepatology 7 914-922.

Chabot J, Walker P \& Pelletier G 1987 Demonstration of epidermal growth factor binding sites in the adult rat pancreas by light microscopic autoradiography. Pancreas 2 653-657.

Damjanov I, Mildner B \& Knowles B 1986 Immunohistochemical localisation of the epidermal growth factor receptor in normal human tissues. Laboratory Investigation 55 588-592.

Dembinski A, Gregory H, Konturek S \& Polanski M 1982 Trophic action of epidermal growth factor on the pancreas and gastroduodenal mucosa in rats. Journal of Physiology 325 35-42.

Friess H, Berberat P, Schilling M, Kunz J, Korc M \& Buchler M 1996 Pancreatic cancer: the potential clinical relevance of alterations in growth factors and their receptors. Journal of Molecular Medicine $\mathbf{7 4}$ $35-42$.

Gu D \& Sarvetnick N 1993 Epithelial cell proliferation and islet neogenesis in IFN- $\gamma$ transgenic mice. Development 118 33-46.

Guo L, Degenstein L \& Fuchs E 1996 Keratinocyte growth factor is required for hair development but not for wound healing. Genes and Development 10 165-175.

Hootman SR \& de Ondarza J 1993 Overview of pancreatic duct physiology and pathophysiology. Digestion 54 323-330.

Korc M 1998 Role of growth factors in pancreatic cancer. Surgical Oncology Clinics of North America 7 25-41.

Korc M, Chandrasekar B, Yamanaka Y, Friess H, Buchier M \& Berger H 1992 Overexpression of the epidermal growth factor receptor in human pancreatic cancer is associated with concomitant increases in the levels of epidermal growth factor and transforming growth factor alpha. Journal of Clinical Investigation 90 1352-1360.

Korc M, Friess H, Yamanaka Y, Kobrin M, Buchler M \& Beger H 1994 Chronic pancreatitis is associated with increased concentrations of epidermal growth factor receptor, transforming growth factor alpha, and phospholipase C gamma. Gut 35 1468-1473.

Krakowski ML, Kritzik MK, Jones EM, Krahl T, Rubin JS, Gu D \& Sarvetnick N 1999 Pancreatic expression of KGF leads to differentiation of islet hepatocytes and proliferation of duct cells. American Journal of Pathology 154 683-692.

Lack E 1989 Primary tumors of the exocrine pancreas. American Journal of Surgery and Pathology 13 66-88.

Logsdon C 1986 Stimulation of pancreatic acinar cell growth by CCK, epidermal growth factor, and insulin in vitro. American Journal of Physiology 251 G487-G494.

Logsdon C 1987 Effects of calcium mediated secretagogues on the growth of pancreatic acinar cells in vitro. Gut 28 (Suppl 1) 117-120.
Mangino M, Hubchak S \& Scarpelli D 1992 Stimulation of DNA synthesis in pancreatic duct cells by gastrointestinal hormones: interaction with other growth factors. Pancreas 7 271-279.

Marti U, Burwen S \& Jones A 1989 Biological effects of epidermal growth factor, with emphasis on the gastrointestinal tract and liver: an update. Hepatology 9 126-138.

Movassat J, Saulnier C \& Portha B 1995 Beta-cell mass depletion precedes the onset of hyperglycaemia in the GK rat, a genetic model of non-insulin diabetes mellitus. Diabetes/Metabolism Reviews 21 365-370.

Rosenberg L \& Vinik A 1989 Induction of endocrine cell differentiation: a new approach to management of diabetes. Journal of Laboratory and Clinical Medicine 114 75-83.

Sanvito F, Herrera P-L, Huarte J, Nichols A, Montesano R, Orci L \& Vassalli J-D 1994 TGF-b1 influences the relative development of the exocrine and endocrine pancreas in vitro. Development $\mathbf{1 2 0}$ 3451-3462.

Sarvetnick N, Liggitt D, Pitts SL, Hansen SE \& Stewart TA 1988 Insulin-dependent diabetes mellitus induced in transgenic mice by ectopic expression of class II MHC and interferon-gamma. Cell $\mathbf{5 2}$ $773-782$

Sessa F, Bonato M, Frigerio B, Capella C, Solcia E, Prat M, Bara J \& Samloff I 1990 Ductal cancers of the pancreas frequently express markers of gastrointestinal epithelial cells. Gastroenterology $\mathbf{9 8}$ $1655-1665$.

Siddiqi I, Funatomi H, Kobrin MS, Friess H, Buchler MW \& Korc M 1995 Increased expression of keratinocyte growth factor in human pancreatic cancer. Biochemical and Biophysical Research Communications 215 309-315.

Steer ML 1989 Classification and pathogenesis of pancreatitis. Surgical Clinics of North America 69 467-480.

Verme TB \& Hootman SR 1990 Regulation of pancreatic duct epithelial growth in vitro. American Journal of Physiology 258 G833-G840.

Vinter-Jensen L, Juhl CO, Teglbjaerg PS, Poulsen SS, Dajani EZ \& Nexo E 1997 Systemic treatment with epidermal growth factor in pigs induces ductal proliferations in the pancreas. Gastroenterology 113 1367-1374.

Wang R \& Bouwens L 1995 Duct- to islet-cell differentiation and islet growth in the pancreas of duct-ligated adult rats. Diabetologia 38 1405-1411.

Wang T, Bonner-Weir S, Oates P, Chulak M \& Simon B 1993 Pancreatic gastrin stimulates islet differentiation of transforming growth factor a-induced ductular precursor cells. Journal of Clinical Investigation 92 1349-1356.

Werner S, Peters K, Longaker M, Fuller-Pace F, Banda M \& Williams L 1992 Large induction of keratinocyte growth factor expression in the dermis during wound healing. Proceedings of the National Academy of Sciences of the USA 89 6896-6900.

Wogensen L, Ma Y-H, Grodsky G, Robertson R, Burton F, Sutcliffe J \& Sarvetnick N 1993 Functional effects of transgenic expression of cholera toxin in pancreatic beta-cells. Molecular and Cellular Endocrinology 98 33-42.

Yamanaka Y, Friess H, Kobrin M, Buchler M, Beger H \& Korc M 1993 Coexpression of epidermal growth factor receptor and ligands in human pancreatic cancer is associated with enhanced tumor aggressiveness. Anticancer Research 13 565-569.

Yi ES, Yin S, Harclerode DL, Bedoya AA, Bikhazi NB, Housley RM, Aukerman SL, Morris CF, Pierce GF \& Ulich TR 1994 Keratinocyte growth factor induces pancreatic ductal epithelial proliferation. American Journal of Pathology 145 80-85.

Received 12 January 1999

Accepted 23 March 1999 